\section{Summary}

An outbreak of a febrile illness confined to a local geographical area within a general practice is described. E.C.H.O. virus 30 was isolated from faeces in a majority of cases. The illness was of rapid onset but lasted only a few days, and the principal symptoms included headache, muscle pains and malaise, vomiting, colicky abdominal pain, and photophobia. Evidence that E.C.H.O. virus 30 was of aetiological significance in the series is discussed. Although E.C.H.O. virus 30 has been found only sporadically over the last six years, the results suggest that it is not a new virus and that adults have an immunity to it.
We are indebted to the technical staff of the department of virology of the Royal Victoria Infirmary for their help.

\section{REFERENCES}

Chin, T. D. Y., Beran, G. W., and Wenner, H. A. (1957). Amer. F. Hyg., 66, 70.

Duncan, I. B. R. (1960). Lancet, 2, 470.

Gardner, P. S., and Cooper, C. E. (1964). F. Hyg. (Lond.), 62, 171.

Wright, A. E., and Hale, J. H. (1961). Brit. med. F., 2, 424.

Grist, N. R., and Bell, E. J. (1967). Hlth Bull. (Edinb.), 25, 18.

Kibrick, S., Meléndez, L., and Enders, J. F. (1957). Ann. N.Y. Acad. Sci., 67, 311

Plager, H., and Decher, W. (1963). Amer. F. Hyg., 77, 26.

Sanford, J. P., and Sulkin, S. E. (1959). Nerw Engl. F. Med., 261, 1113. Tyrrell, D. A. J., and Snell, B. (1956). Lancet, 2, 1028.

Wright, A. E., et al. (1961). Newc. med. F., 27, 13.

\title{
Calf Muscle Denervation for Intermittent Claudication*
}

\author{
N. V. ADDISON, $\dagger$ M.B., F.R.C.S.
}

Brit. med. F., 1967, 4, 776-778

It is now a well-established fact that the ideal treatment for femoropopliteal occlusions which cause intermittent claudication in the calf is a bypass graft. An autogenous saphenous vein is undoubtedly the best type of graft to use with good and lasting results (Darling et al., 1967). The indications for inserting a graft usually depend on the individual surgeon, who may operate for intermittent claudication which is not particularly disabling. Others may limit the procedure to those with severe claudication, rest pain, or impending gangrene (Shucksmith and Addison, 1962). The reversed saphenous vein bypass graft is usually taken from the common femoral to the distal popliteal artery behind or below the knee joint. The problem arises when the distal popliteal artery is grossly diseased or totally blocked. Under these circumstances it may be possible to take the graft to the posterior tibial or peroneal arteries if the saphenous vein is left in situ. If both distal popliteal and tibial vessels are unsuitable for grafting then only palliative treatment can be considered. Claudication can be relieved or the claudication distance increased by inactivation of the calf muscles where the pain develops. Two operations can be performed to effect this inactivation, one by Achilles tenotomy (Boyd and Bloor, 1960) and the other by denervation of the calf muscles.

If these muscles are paralysed the patient learns to use other muscles, including the hamstrings, when walking. Learmonth and Slessor (1952) describe this procedure of myoneurectomy and claim that patients obtain a walking distance some five times greater than preoperative distances.

If the distal vessels are blocked and there is severe rest pain in the foot or calf then an above-knee or Gritti-Stokes amputation may be necessary, though a lumbar sympathectomy is well worth trying, especially if pain is relieved by a medical sympathectomy (Martin, 1963). Obviously rest pain cannot be relieved by inactivation of the calf muscles, but if it is localized to a small area in the foot, treatment by a selective peroneal or anterior tibial neurectomy may help.

I have adopted the method of calf muscle denervation for patients with popliteal or tibial occlusions, and for some older patients with calf pain, as an alternative to a bypass graft. This

\footnotetext{
- Based on a lecture given at the invitation of the Professor of Surgery, Jefferson Medical College, Philadelphia, U.S.A., on 25 April 1967. t Consultant Surgeon, Royal Infirmary, Bradford.
}

paper is based on the first 40 denervations carried out during the past four years.

\section{Cause of Ischaemic Pain in Calf Muscles}

The cause of intermittent claudication is a relative anoxia of the muscles, and the importance of this anoxia was shown by Pickering and Wayne (1934). They found that by exercising muscles of an anaemic subject with no evidence of arterial disease characteristic pain of intermittent claudication could be produced. The clinical experiments of Lewis (1932) indicate that the direct cause of the pain is not oxygen lack itself but the stimulation of sensory nerves by the metabolic products of muscular activity. When the blood supply is inadequate and oxygenation therefore deficient, metabolic products accumulate. Lewis referred to the pain stimulus as "factor P." The nature of the chemical pain factor is unknown but is probably acid, and ingestion of sodium bicarbonate was found to increase the amount of exercise required to cause pain.

\section{Nerve Supply of Calf Muscles}

In a so-called motor nerve supplying a limb muscle at least 30 to $40 \%$ of the fibres are sensory in function and have their cell bodies in the dorsal root ganglia of the segmental nerves.

The endings of the afferent fibres in striated muscle vary a great deal in structure. The simplest ones are very fine nonmyelinated nerve fibres with no specific ending. Some run in perivascular plexuses, and others are found in connective tissue, and it has been suggested that these are pain fibres (Bowden, 1960).

The medial popliteal nerve, arising from the fourth and fifth lumbar nerves and the first, second, and third sacral nerves, supplies the two heads of the gastrocnemius and the soleus. In the popliteal fossa it is concealed at first by the semimembranosus and other hamstring muscles. It passes superficial to the popliteal vessels from the lateral to the medial side, and is thereafter found deep to the popliteus muscle under cover of the gastrocnemius and plantaris. Two branches arise in the fossa, one for each head of the gastrocnemius, and usually enter these muscles at the borders of the popliteal fossa. A nerve for 
the soleus enters the superficial surface of the muscle near its proximal border and a branch from the posterior tibial nerve (which begins at the distal border of the popliteus) enters the soleus on its deep surface near the middle of the leg. The soleus can never be completely denervated unless this branch is divided. At the inferior angle of the popliteal fossa the medial popliteal nerve gives off the sural nerve, which leaves the fossa by passing downwards between the two heads of the gastrocnemius and continues down the posterior aspect of the calf with the short saphenous vein.

\section{Operative Procedure}

The patient lies in a prone position under general anaesthesia which must be light ; under no circumstances must a longacting muscle relaxant be used, because the nerves are identified by pinching them with artery forceps to stimulate immediate contraction of the muscles. If these are paralysed by longacting relaxants, then the calf muscle nerves cannot be properly identified and there is the danger of dividing the wrong nerve. The sural nerve can be mistaken for a nerve to the calf muscles, and if this is divided then anaesthesia will result on the lateral side and back of the distal third of the leg, ankle, and heel and on the lateral border of the foot.

An incision about 2 in. $(5 \mathrm{~cm}$.) in length is made in the midline in the lower part of the popliteal fossa. The deep fascia is divided and the heads of the gastrocnemius are held apart with a self-retaining retractor. Care must be taken not to damage the sural nerve or popliteal veins that may lie superficial to the medial popliteal nerve, which is identified before dissecting out the nerves to the muscles.

There are usually three nerves to be divided and ligated with thread (see Fig.). Coagulation diathermy should be avoided and

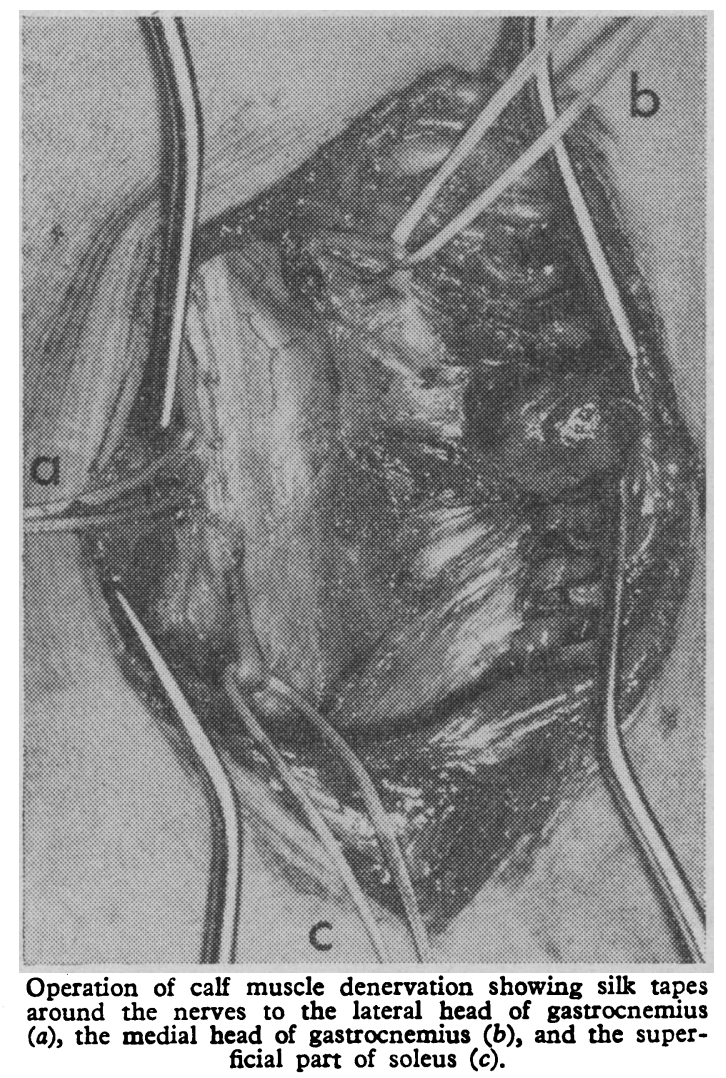

haemostasis should be complete before suturing the deep fascia and skin. If a lumbar sympathectomy is to be carried out then the patient is turned over and this is proceeded with. The patient is got out of bed as soon as he becomes fully conscious, the following day he is encouraged to walk up and down the ward, and he is discharged 48 hours after operation. It is most important to walk immediately, wearing a firm crêpe bandage to support the calf.

\section{Selection of Cases for Operation}

Any patient with disabling claudication whose arteriogram showed occluded distal popliteal or tibial arteries was considered for muscle denervation, provided that the symptoms had been present for at least one year, as about 50 to $60 \%$ of patients with untreated claudication improve spontaneously up to 12 months after the onset, owing to the development of a collateral circulation. The presence of calcification on a plain radiograph of the lower limb was also thought to be unsuitable for a vein graft, though some surgeons do not regard calcification as a serious hazard.

It is important to select only those patients with pain in the calf. If claudication occurs in the buttocks and thighs as well then surgery of the aortoiliac region is necessary to relieve the pain. Unilateral calf claudication was desirable for a good result as it was in Boyd and Bloor's (1960) selection of cases for Achilles tenotomy. It is useful to choose a fairly intelligent patient who will understand the nature and purpose of the operation.

If the foot was cold then a lumbar sympathectomy was carried out at the same time as the denervation of the calf muscles.

\section{Results and Follow-up}

In the present series 40 patients have undergone calf muscle denervation, and two of these were bilateral. Their ages varied from 45 to 70 years, the majority being 55 to 64 (Table I). There were four failures in the first six months, due to poor selection of cases, and two of these failures had bilateral denervations.

TABle 1.-Age of 40 Patients Undergoing Calf Muscle Denervation

\begin{tabular}{lllll|c|c|c}
\hline Age $\ddot{\text { No. of patients }}$. & $\because$. & $\because$ &.. &. & $45-54$ & $55-64$ & $65-70$ \\
\end{tabular}

The remaining 36 patients have been followed up at regular intervals for a minimum of six months and a maximum of 44 months (Table II). There have so far been no deaths in the series.

TABLE II.-Follow-up of 36 Patients After Calf Muscle Denervation

\begin{tabular}{|c|c|c|c|c|c|c|}
\hline $\begin{array}{l}\text { Time (years) .. } \\
\text { No. of patients }\end{array}$ & & $\because$. & $\begin{array}{c}\text { Less than } 1 \\
8\end{array}$ & $\begin{array}{l}1-2 \\
12\end{array}$ & $\frac{2-3}{12}$ & $\underset{4}{\text { Over }} 3$ \\
\hline
\end{tabular}

The claudication distance preoperatively was recorded and in 18 patients was 50 to 100 yards (45 to 90 metres), and in 22 patients 101 to 200 yards ( 91 to 180 metres) (Table III). After operation patients were seen at three-monthly intervals and asked how far they were able to walk on the flat before pain developed. The distances recorded were based on the patient's

TABLe III.-Claudication Distance Before and After Muscle Denervation

\begin{tabular}{c|c|c}
\hline \multicolumn{2}{c|}{ Distance } & No. of Patients \\
\hline Yards & Metres & \\
\hline \multicolumn{3}{|c}{ Before muscle denervation } \\
$50-100$ & $45-90$ & 18 \\
$101-200$ & $91-180$ & 22 \\
\multicolumn{3}{c}{ After muscle deneroation } \\
No change & $0-275$ & $4(10 \%)$ including 2 bilateral \\
$0-300$ & $6(15 \%)$ \\
$301-600$ & $276-550$ & $8(20 \%)$ \\
$601-2,000$ & $551-1,830$ & $12(30 \%)$ \\
No limit & & $10(25 \%)$ \\
\end{tabular}


subjective assessment, which is an inaccurate method of judging results, especially in estimating walking distances less than 500 yards (455 metres). When a patient stated that he could walk over half a mile ( 800 metres) or indefinitely without pain, the recording of results was made much easier. In the earlier cases an attempt was made to estimate improvement by recording pain when patients were asked to step up and down on to a box $1 \mathrm{ft}$. $(30 \mathrm{~cm}$.) high before and after operation, but the test was not helpful and was therefore abandoned.

Preoperative arteriography carried out in 38 patients showed that 32 had unilateral femoropopliteal blocks, the remaining six being occluded in both legs. In the bilateral occlusions there were four early failures and the other two were not very successful, as their increased walking distance was less than 300 yards (275 metres).

In 20 patients there was associated aortoiliac disease but not occlusions, but this did not appear to have any effect on the final results in 17 . In the other three patients there was only slight improvement postoperatively.

Those patients with the most severe disease demonstrated radiologically and a preoperative claudication distance of less than 100 yards ( 90 metres) did not benefit from surgery as well as those with less severe disease and a longer claudication distance up to 200 yards (180 metres).

It is apparent that the early results are most encouraging, and that at least $70 \%$ are able to walk 500 yards (455 metres) or more without pain, and that the long-term results are satisfactory up to three years after operation (Table III).

\section{Complications of Muscle Denervation}

There were two cases of deep thrombophlebitis seen earlier on in the series and both responded rapidly to anticoagulant therapy. One case of deep thrombophlebitis in the calf was seen 18 months after operation, but the patient had been able to walk indefinitely without pain after operation until the onset of the attack, which resolved with rest and a firm supporting bandage. One case of pulmonary embolism was recorded in one of the patients suffering from deep thrombophlebitis.

In one case early on in the series a haematoma needed to be evacuated surgically, and in another patient the lateral popliteal nerve was accidentally crushed, but this recovered fully after almost a year. Complete haemostasis, a firm bandage, and immediate ambulation help to eliminate any complications that may arise.

\section{Discussion}

The results in this series would appear more favourable than those undergoing Achilles tenotomy reported by Boyd and Bloor (1960). In 72 patients they reported complete relief of pain in only $22 \%$, temporary relief for one year in $21 \%$, and immediate failure in $57 \%$. Claudication developing elsewhere in the same leg or other leg accounted for $50 \%$ of their immediate failures. They suggested that their results could have been better with a more careful selection of cases for operation.

Disadvantages of Achilles tenotomy include early union by fibrous tissue of the ends of the divided tendon leading to a return of symptoms. Another disadvantage is the difficulty of walking immediately, as patients must learn to stand with confidence before trying to walk. After calf muscle denervation they can walk immediately, though they all have a slight limp and a few have needed to use a stick, but all regarded this as a small price to pay in return for relief of pain.
Muscle denervation has a more logical approach to the relief of pain than Achilles tenotomy, and its effective action may be due to three factors: (1) paralysis of the gastrocnemii and part of the soleus muscles with wasting; (2) division of somatic afferent pain fibres in the mixed motor nerves ; and (3) division of sympathetic afferent pain fibres in the mixed motor nerves. It is possible that division of the motor nerves destroys sympathetic as well as somatic afferent fibres, and this relieves pain to some extent. Relief of intermittent claudication after a lumbar sympathectomy alone may be due to division of afferent pathways, since some patients claim that though their halting distance is unchanged the severity of the pain is diminished (Myers and Irvine, 1966). A lumbar sympathectomy was carried out simultaneously in 12 of the 40 denervations, and it was recorded that six of these patients could walk indefinitely without pain after operation.

In assessing the results of calf muscle denervation it is stressed that improvement was based entirely on the patient's subjective assessment of walking distance without pain. Twenty-two patients ( $55 \%$ ) stated emphatically that they could walk about half a mile ( 800 metres), or indefinitely, and these were judged to be very successful. A further $8(20 \%)$ claimed that their walking distance had increased up to three times their preoperative distance. In view of the difficulty of estimating short distances with any accuracy, these results were not judged as successful as those who could walk half a mile (800 metres) or indefinitely. On the other hand, these eight patients definitely benefited from surgery, compared with the remaining six who had only slight improvement of walking distance up to 300 yards (275 metres).

\section{Summary}

Patients with intermittent claudication in the calf caused by femoropopliteal occlusions are usually treated with bypass vein grafts, but this procedure is impracticable if the distal popliteal and tibial arteries are grossly diseased or blocked.

An alternative operation of calf muscle denervation is aescribed in 40 patients who have been followed up for six months to over three years. There were four early failures due to poor selection of patients for this procedure.

Early results are encouraging, and $70 \%$ of patients are able to walk at least 500 yards (455 metres) and $25 \%$ are able to walk indefinitely without pain. The long-term results would appear to be satisfactory.

Calf muscle denervation is a simple operation with little morbidity, and is advised for inoperable femoropopliteal occlusions. The operation can be performed selectively in operable cases in the older age group.

I wish to thank Mr. P. Harrison for the illustration, and Mr. C. L. O. Macalister for his helpful advice.

\section{REFERENCES}

Bowden, R. E. M. (1960). Brit. med. f., 1, 671.

Boyd, A. M., and Bloor, K. (1960). Ibid., 1, 548.

Darling, R. C., Linton, R. R., and Razzuk, M. A. (1967). Surgery, 61, 31.

Learmonth, J., and Slessor, A. J. (1952). Brit. med. Bull., 8, 375.

Lewis, T. (1932). Arch. intern. Med., 49, 713.

Martin, P. (1963). Indications and Techniques in Arterial Surgery. London.

Myers, K. A., and Irvine, W. T. (1966). Brit. med. F., 1, 879.

Pickering, G. W., and Wayne, E. J. (1934). Clin. Sci., 1, 305.

Shucksmith, H. S., and Addison, N. V. (1962). Brit. med. F., 2, 1144 